\title{
OS EXERCíCIOS DA SUBJETIVIDADE: as reificações inocentes e as reificações estranhadas
}

\author{
Ricardo Antunes
}

\begin{abstract}
Este texto explora, analítica e empiricamente, a problemática da alienação e (ou) estranhamento, procurando auxiliar na intelecção das bases sócio-históricas que propiciam o seu florescimento dentro da empresa capitalista moderna. Para tanto realiza os seguintes movimentos: primeiro, partindo das concepções teóricas seminais de Marx, procura indicar as formas diferenciadas assumidas pela alienação e (ou)estranhamento, ao longo do século XX e inícios do século XXI, explorando alguns dos seus traços principais. Em seu segundo movimento, esboça uma fenomenologia da subjetividade, explorando, como hipótese, as ricas possibilidades analíticas existentes na obra de maturidade de Lukács, em particular suas noções de reificações inocentes e reificações estranhadas, como pistas férteis a compreensão desse fenômeno social no capitalismo de nossos dias.

PALAVRAS-CHAVE: alienação e estranhamento, capitalismo e reificação, taylorismo, toyotismo e subjetividade.
\end{abstract}

O tema proposto para esta conferência - a questão da alienação contemporânea - é reflexão complexa e, ao mesmo tempo, crucial de nosso tempo, o que me obriga a desenhar algumas notas que mantêm, em si, uma clara dimensão inter-relacional.

Sabemos que o trabalho assalariado, responsável pela interiorização das fetichizações e coisificações da classe-que-vive-do-trabalho, expandiu-se com o capitalismo da fase maquínica, parcelar, industrial, desde meados do século XVIII, acarretando profundas repercussões na subjetividade do trabalho.

Devemos a Marx a mais decisiva reflexão acerca do complexo social da alienação (e, em particular, do estranhamento): ${ }^{1}$ a sociabilidade do ca-

\footnotetext{
* Doutor em Sociologia pela USP. Professor Titular de Sociologia no Instituto de Filosofia e Ciências Humanas da UNICAMP. Pesquisador do CNPq.

Caixa Postal 6110 - IFCH-UNICAMP. Barão Geraldo. Cep: 13083-970 - Campinas, SP - Brasil - Caixa-Postal: 6110. rantunes@unicamp.br

${ }^{1}$ Sobre as similitudes e diferenças entre Entäusserung e Entfremdung em Marx, ver os excelentes estudos (ainda que com abordagens relativamente diferenciadas) de Mészáros (2006) e de Ranieri (2001). Mészáros utiliza o conceito de alienação, e não o estranhamento, como eixo analítico central. Mas faz, em seu livro, uma nota de rodapé onde apresenta uma diferenciação importan-
}

pital é responsável pelo advento da forma trabalho assalariado, do trabalho-mercadoria ou, de modo mais preciso, da generalização da mercadoria força de trabalho. Em suas palavras:

O trabalhador se torna tanto mais pobre quanto mais riqueza produz, quanto mais a sua produção aumenta em poder e extensão. O trabalhador se torna uma mercadoria tão mais barata quanto mais mercadorias cria. Com a valorização do mundo das coisas (Sachenwelt) aumenta em proporção direta a desvalorização do mundo dos homens (Menschenwelt). O trabalho não produz somente mercadorias; ele produz a si mesmo e ao trabalhador como uma mercadoria, e

te, que aqui caminha em confluência com nossa opção. Em suas palavras: quando a "ênfase recai sobre a 'externalização' ou 'objetivação', Marx usa o termo Entäusserung (ou termos como Vergegenständlichung [objetivação]), ao passo que Entfremdung é usado quando a intenção do autor é ressaltar o fato de que o homem está encontrando oposição por parte de um poder hostil, criado por ele mesmo, de modo que ele frustra seu próprio propósito" (Meszáros, 2006, p.20). Neste texto, optamos traduzir por estranhamento o termo Entfremdung, dada a utilização, por Marx, acentuando a dimensão de negatividade. E alienação para o termo Entäusserung, que pode significar também exteriorização - e, como tal, parte constitutiva da atividade humana, diverso do estranhamento que é sempre claramente marcado pela negatividade, dada pela vigência do trabalho abstrato e assalariado sob o capitalismo. Em nosso trabalhos anteriores, pudemos discorrer mais detidamente nesta dilemática (Antunes, 2010, 2010a). 
isto na medida em que produz, de fato, mercadorias em geral (Marx, 2004, p.80).

Isto porque, o objeto que o trabalho produz, o seu produto, acrescenta Marx,

... se lhe defronta como um ser estranho, como um poder independente do produtor. O produto do trabalho é o trabalho que se fixou num objeto, fez-se coisal (sachlich), é a objetivação (Vergegenständlichung) do trabalho. A efetivação (Verwirklichung) do trabalho é a sua objetivação. Esta efetivação do trabalho aparece ao estado nacional-econômico como desefetivação (Entwirklichung) do trabalhador, a objetivação como perda do objeto e servidão ao objeto, a apropriação como estranhamento (Entfremdung), como alienação (Entäusserung) (2004, p.80) .

A efetivação do trabalho, portanto, é sua própria situação de desefetivação (p.80), o que significa dizer que se trata de uma efetividade que se configura como perda, que o trabalhador se desrealiza, se desefetiva e se estranha no processo de trabalho. Conforme as palavras de Marx:

A objetivação tanto aparece como perda do objeto que o trabalhador é despojado dos objetos mais necessários não somente à vida, mas também dos objetos do trabalho. Sim, o trabalho mesmo se torna um objeto, do qual o trabalhador só pode se apossar com os maiores esforços e com as mais extraordinárias interrupções. A apropriação do objeto tanto aparece como estranhamento (Entfremdung) que, quanto mais objetos o trabalhador produz, tanto menos pode possuir e tanto mais fica sob o domínio do seu produto, do capi-

Seu estranhamento, portanto, se efetiva sempre pela dimensão de negatividade, sentimento de perda e desefetivação, presente no processo de produção capitalista, uma vez que o produto gerado pelo trabalho não pertence ao seu criador.

O estranhamento do trabalhador em seu objeto se expressa, segundo a economia política, na medida em que

... quanto mais o trabalhador produz, menos tem para consumir; que quanto mais valores cria, mais sem-valor e indigno ele se torna; quanto melhor formado o seu produto, tanto mais deformado ele fica; quanto mais civilizado seu objeto, mais bárbaro o trabalhador; que quanto mais podero- so o trabalho, mais impotente o trabalhador se torna; quanto mais rico de espírito o trabalho, mais pobre de espírito e servo da natureza se torna o trabalhador (p.82) .

Aqui está, então, a primeira manifestação do estranhamento em relação à própria natureza humana. E esse primeiro momento, mais visível em seu ser fenomenológico, encobre sua segunda manifestação: o trabalho também não se reconhece em sua própria atividade produtiva. Trata-se de um trabalho que, em sua atividade de criação, expressa um momento de desefetivação, interiorizando o fetichismo da sociedade da mercadoria presente no próprio processo de trabalho.

Ou seja, a exteriorização do trabalhador sob a modalidade do estranhamento apresenta-se inicialmente em "sua relação com os produtos do seu trabalho”. Mas, acrescenta Marx, o estranhamento do trabalho não se expressa somente no resultado do processo produtivo, mas no próprio ato da produção, na atividade produtiva em si mesma.

A pergunta de Marx é clara: como poderia o trabalhador se encontrar

... alheio (fremd) ao produto da sua atividade se no ato mesmo da produção ele não se estranhasse a si mesmo? O produto é, sim, somente o resumo (Resumé) da atividade, da produção. Se, portanto, o produto do trabalho é a exteriorização, então a produção mesma tem de ser a exteriorização ativa, a exteriorização da atividade, a atividade da exteriorização. No estranhamento do objeto do trabalho resume-se somente o estranhamento, a exteriorização na atividade do trabalho mesmo (p.82).

Essa processualidade faz aflorar seu terceiro momento, no qual o ser social que trabalha - e que deveria estar realizando uma atividade vitalse desrealiza e não se reconhece em sua relação entre "vida do gênero" e "vida individual”, o que leva à quarta dimensão do complexo social do estranhamento: o ser se estranha em relação ao próprio ser, ele se separa de seu ser genérico (p.85). ${ }^{2}$

2 "O trabalho estranhado faz, por conseguinte: 1) do ser genérico do homem, tanto da natureza quanto da faculdade genérica espiritual dele, um ser estranho a ele, um meio da sua existência individual. Estranha do homem o seu próprio corpo, assim como a natureza fora dele, ta como a sua essência espiritual, a sua essência humana 
Esses quatro momentos, intrinsecamente articulados e constitutivos do processo de estranhamento em Marx, foram aqui muito sinteticamente apresentados a partir dos Manuscritos Econômico-Filosóficos e do excepcional capítulo I de OCapital (particularmente no item que trata do fetichismo da mercadoria), uma vez que, nesse estudo de mais de duas décadas depois, Marx retoma e explora analiticamente o problema da reificação e da coisificação com ainda maior adensamento ontológico, dada a concretude do mundo fabril e da economia política que analisou detalhadamente.

Está nos Manuscritos de 1844 a primeira reflexão marxiana articulando reflexão filosófica com elementos (ainda que embrionários) da economia política. Ele apresenta essa síntese forte, que uma vez mais preferimos citar:

Em que consiste, então, a exteriorização (Entäusserung) do trabalho?

Primeiro, que o trabalho é externo (äusserlich) ao trabalhador, isto é, não pertence ao seu ser, que ele não se afirma, portanto, em seu trabalho, mas nega-se nele, que não se sente bem, mas infeliz, que não desenvolve nenhuma energia física e espiritual livre, mas mortifica sua physis e arruína o seu espírito.

Do que se depreende que "o trabalhador só se sente, por conseguinte e em primeiro lugar, junto a si [quando] fora do trabalho e fora de si [quando] no trabalho. Está em casa quando não trabalha e, quando trabalha, não está em casa. O seu trabalho não é portanto voluntário, mas forçado, trabalho obrigatório."

Ao contrário de efetivar-se como exercício de uma atividade vital, a satisfação de uma carência, ele se converte em apenas um meio para satisfazer carências fora dele. Sua condição de estranhamento é tão evidente que, "tão logo inexista coerção física ou outra qualquer, foge-se do trabalho como de uma peste", na célebre formulação marxiana (p.82-83).

Seu trabalho externo, sua forma de exteriorização assume, então, a conformação de "um

2) uma consequência imediata disto, do homem estar estranhado do produto do seu trabalho, de sua atividade vital e de seu ser genérico é o estranhamento do homem pelo [próprio] homem. Quando o homem está frente a si mesmo, defronta-se com ele o outro homem. O que é produto da relação do homem com o seu trabalho, produto de seu trabalho e consigo mesmo, vale como relação do homem com outro homem, como o trabalho e o trabalho de auto-sacrifício, de mortificação” (p.83).

Assim, a externalidade do trabalho aparece para o trabalhador não como resultado de seu trabalho, mas de um outro, visto que tanto o produto como seu próprio trabalho não lhe pertencem, mas sim a um outro. E, então, Marx procura um símile na religião:

... a auto-atividade da fantasia humana, do cérebro e do coração humanos atua independentemente do indivíduo e sobre ele, isto é, como uma atividade estranha, divina ou diabólica, assim também a atividade do trabalhador não é a sua auto-atividade. Ela pertence a outro, é a perda de si mesmo (p.83).

Sua conclusão é, uma vez mais, arguta e caustica: o trabalhador só se sente como ser livre e ativo em suas funções animais, tais como comer, beber e procriar, e, quando exerce suas funções humanas, se sente como os animais. $O$ animal se torna humano e o humano, animal.

Mas, como Marx sabe que esse terreno é gelatinoso, acrescenta imediatamente:

... comer, beber e procriar etc. são também funções genuinamente humanas e sociais. Porém, na abstração que as separa das demais esferas da atividade humana, ao convertê-las em finalidades últimas e exclusivas, age como os animais (p.83).

Anteriormente, em seus "Extratos de Leitura sobre J. Mill", nos estudos que antecederam a realização dos Manuscritos de 1844, Marx formulou (provavelmente) pela primeira vez de modo mais articulado sua concepção de alienação e estranhamento:

Meu trabalho seria livre projeção exterior de minha vida, portanto desfrute de vida. Sob o pressuposto da propriedade privada (em troca) é estranhamento de minha vida, posto que trabalho para viver, para conseguir os meios de vida. Meu trabalho não é vida. [...] Uma vez pressuposta a propriedade privada, minha individualidade se torna estranhada a tal ponto, que esta atividade se torna odiosa, um suplício e, mais que atividade, aparência dela; por consequência, é também uma atividade puramente imposta e o único que me obriga a realizá-la é uma necessidade extrínseca e acidental, não a necessidade interna e necessária (Marx, 1978, p.293, 299). 
Desse modo, o estranhamento é a realização uma relação social fundada na "abstração da natureza específica, pessoal" do ser social que "atua como homem que se perdeu a si mesmo, desumanizado" (p.278).

Essa reflexão acabou por receber, em sua obra de maturidade maior, $O$ Capital, um adensamento imprescindível para se compreender o fenômeno social da alienação e do estranhamento, ao discorrer sobre o fetichismo da mercadoria vigente no capitalismo, em que as relações sociais estabelecidas entre os produtores acabam por assumir a forma de relação entre os produtos do trabalho. A relação social estabelecida entre os seres sociais adquire, por força do sistema de metabolismo social existente, a forma de uma relação entre coisas.

Eaqui aflora o problema crucial do fetichismo:

A igualdade dos trabalhos humanos assume a forma material da igual objetividade de valor dos produtos de trabalho; a medida do dispêndio de forças de trabalho do homem, por meio de sua duração, assume a forma da grandeza de valor dos produtos de trabalho; finalmente, as relações entre os produtores, em que aquelas características sociais de seus trabalhos são ativadas, assumem a forma de uma relação social entre os produtos de trabalho (Marx, 1971, p.71).

Dada a prevalência do trabalho abstrato em relação ao trabalho concreto, tem-se, então, o afloramento do caráter misterioso ou fetichizado da mercadoria, que encobre as dimensões sociais do próprio trabalho, mostrando-as como inerentes aos produtos do trabalho.

Ao mascarar as relações sociais existentes entre os trabalhos individuais e o trabalho total, o sistema de metabolismo social do capital apresenta-as "naturalmente" como sendo expressão de relações entre objetos coisificados, o que leva Marx a afirmar que "não é mais nada que determinada relação social entre os próprios homens que para eles aqui assume a forma fantasmagórica de uma relação entre coisas" (1971, p.71).

Na vigência da lei do valor de troca, o vinculo social entre as pessoas se transforma em uma relação social entre coisas: a capacidade pessoal transfigura-se em capacidade das coisas. Trata-se, portanto, de uma relação reificada e coisificada entre os seres sociais.

Não parece crível que esse cenário tenha desaparecido da nossa história recente, uma vez que, em seus traços essenciais, esse trabalho assalariado, abstrato e fetichizado adentrou os séculos XIX e XX.

E foi nesse último século que vivenciamos a consagração da sociedade do trabalho abstrato e assalariado. Com o taylorismo-fordismo, a continuidade avançada da maquinaria e da grande indústria analisadas por Marx, consolidou-se a chamada sociedade do automóvel, que se espalhou pelo mundo.

$* * *$

Como sabemos, Taylor, o mestre da engenharia científica do capital, propugnava que os trabalhadores deveriam ser controlados rigidamente pelos tempos e movimentos, sob comando de uma camada de gestores, administradores e engenheiros que elaboravam e concebiam a produção que, por sua vez, seria executada pela classe dos trabalhadores manuais. E esse é o cerne da teoria tayloriana do trabalho: os engenheiros concebem e os trabalhadores manuais - que certa vez Taylor denominou como "gorilas amestrados" - executam. Concepção e manualidade, elaboração e execução, aprofundando, desde o espaço microcósmico da produção, a divisão social do trabalho.

E Ford aplicou a engenharia de Taylor em sua produção seriada e homogeneizadora, de modo a aumentar as economias de escala e, consequentemente, os lucros oriundos da produção automotiva, consolidando a sociedade de massa do século XX.

Tratou-se, então, como já pude dizer anteriormente, ${ }^{3}$ de um casamento que deu certo: Taylor e Ford, o engenheiro científico e o fabricante de automóveis. Eles foram responsáveis pela ampliação e generalização das formas de estranhamento e

Antunes, 2009, p.223, no qual retomo várias ideias neste texto. 
reificação que marcaram fundo o exercício da subjetividade do trabalho no espaço produtivo, inicialmente fabril e depois para a totalidade dos espaços geradores de valor.

Entretanto, uma análise mais cuidadosa acerca do trabalho tayloriano-fordista pode apresentar certas nuances: se ele era predominantemente maquinal, parcelar, especializado, fragmentado e prescrito, contraditoriamente, ele assumia uma versão mais contratualista, relativamente regularizada e provida de direitos, resultado de lutas históricas da classe trabalhadora ao longo de vários séculos. Era, portanto, uma variante de trabalho fetichizado, mas regulamentado. Ou seja: no que concerne à sua materialidade, à forma de (des)efetivação do trabalho, sua conformação fragmentada, sua separação em relação ao produto do seu próprio trabalho, bem como as diversas manifestações de estranhamento, que indicamos na primeira parte deste texto, acabavam por acarretar uma forte repercussão em sua subjetividade, que se configurava como crescentemente coisificada e reificada.

Mas, numa processualidade aparentemente contraditória, esse mesmo trabalho de base tayloriano-fordista era dotado de maior regulação, contratualidade e seguridade, resultantes, nunca é demais reiterar, de suas lutas históricas pela regulamentação do trabalho frente aos ditames do capital. As lutas pela regulamentação da jornada de trabalho, pelo direito de greve e organização sindical e política independentes e autônomas, pelo salário igual para trabalho igual entre homens e mulheres, são alguns dos inúmeros exemplos de luta do trabalho pelos seus direitos frente ao capital.

Suas formas de reificação, entretanto, que Lukács e Gramsci compreenderam tão vivamente, reafirmavam, em seus traços essenciais, a alienação estranhada, tal qual fora apresentada por Marx, já em meados do século XIX, agora ampliada, uma vez que a própria sociedade assumia a expressão prolongada do microcosmo fabril.

Uma leitura atenta dos capítulos de OCapital, no qual Marx discorre analiticamente sobre a maquinaria e a grande indústria, poderá constatar que o taylorismo e o fordismo têm mais elementos de continuidade do que de descontinuidade em relação às engrenagens propulsoras da grande indústria do século XIX. E acrescentava que a fábrica moderna de massa só poderia funcionar com um exército de feitores controlando o trabalho, exercitando uma modalidade de despotismo fabril.

Em História e Consciência de Classe, no ensaio A Coisificação e a Consciência do Proletariado, Lukács demonstrou como a fragmentação tayloriana do trabalho penetrava até a "alma do trabalhador", alicerçando os fundamentos da coisificação, numa complexa articulação entre materialidade e subjetividade operária. E Gramsci, em seu ensaio Americanismo e Fordismo, explorou a ideia do homem integral para o capital, onde até o controle da sexualidade era concebido, de modo a canalizar a virilidade masculina na produção maquínica.

Tempos Modernos de Chaplin é, no universo fílmico, a mais genial fotografia dessa engrenagem que floresce no chão de fábrica desumanizada. $A$ Classe Operária vai ao Paraíso, de Elio Petri, ainda que sem o mesmo estatuto de classicidade do filme anterior, retrata, de modo forte, o universo fabril tayloriano-fordista e suas repercussões na subjetividade dos trabalhadores no contexto do "outono quente” das lutas operárias da Itália em 1969.

O crescente processo de eliminação de trabalho vivo pelo trabalho morto, de substituição de trabalhadores por tecnologia maquínica, foi outro traço central na sujeição que a máquina-ferramenta - em verdade, a lógica movida pelo sistema do capital - impôs ao trabalho, reduzindo e mesmo eliminando sua destreza oriunda da fase artesanal e mesmo manufatureira, consolidando o processo de desumanização do trabalho, ou, mais rigorosamente, a "desantropomorfização do trabalho", para usar uma formulação do Lukács presente em sua obra de maturidade, Ontologia do Ser Social.

E foi desse modo que, ao longo do século $\mathrm{XX}$, a lógica maquínica da fábrica prolongou-se amplamente para o conjunto da sociedade, levando sua engenharia produtiva para quase todas as partes do mundo urbano, industrial e de serviços.

Mas, a crise estrutural que se abateu nas economias capitalistas centrais a partir dos inícios 
dos anos 1970 levou, dentre tantas metamorfoses e mutações, a uma monumental reestruturação capitalista de amplitude global, com profundas mudanças no processo de produção e do trabalho. Germinou a denominada "empresa enxuta, flexível”, com seu receituário que, se não altera a forma de ser do capital, modifica, em muitos aspectos, as engrenagens e os mecanismos da acumulação, com fortes consequências na subjetividade do ser social que trabalha, adicionando novos elementos ao fenômeno social da alienação e do estranhamento, através da identificação das personificações do trabalho como personificações do capital. É por isso que, hoje, nenhuma fábrica ou empresa usa, em sua terminologia gerencial, as denominações operários, trabalhadores, mas recorre à apologética presente na ideologia dos "colaboradores", "parceiros", "consultores" ou denominações assemelhadas.

Em seus traços mais gerais, é possível dizer que a empresa da era da flexibilidade liofilizada articula um conjunto de elementos de continuidade e de descontinuidade em relação ao empreendimento tayloriano e ou fordista. Ele se estrutura com base em uma organização do trabalho que resulta da introdução de técnicas de gestão da força de trabalho próprias da fase informacional; desenvolve uma estrutura produtiva mais flexível, recorrendo frequentemente à deslocalização produtiva, à terceirização (dentro e fora das empresas); utiliza-se do trabalho em equipe, das "células de produção", dos "times de trabalho", além de incentivar, de todos os modos, o "envolvimento participativo", uma participação que preserva, em seus traços essenciais, os condicionantes anteriormente apresentados (Antunes, 2010).

Conforma-se, então, uma nova forma de organização e controle do trabalho cuja finalidade central é, de fato, a intensificação do processo laborativo, com ênfase também no envolvimento qualitativo dos trabalhadores e trabalhadoras, em sua dimensão cognitiva, procurando reduzir ou mesmo eliminar os espaços de trabalho improdutivo, que não criam valor, especialmente nas atividades de manutenção, acompanhamento, inspeção de qualidade, etc., funções que passaram a ser diretamente incorporadas ao trabalhador produtivo. Desse modo, reengenharia, lean production, team work, eliminação de postos de trabalho, aumento da produtividade, qualidade total, "metas", "competências", "parceiros"e "colaboradores", são partes constitutivas do ideário e da pragmática cotidiana da "empresa moderna".

Se, no apogeu do taylorismo-fordismo, a pujança de uma empresa estava representada pelo número de trabalhadores que nela atuavam, de modo contrário, pode-se afirmar que a empresa que tipifica a fase da flexibilidade liofilizada é aquela que aglutina o menor contingente de trabalho vivo e concentra o maior volume de trabalho morto, corporificado no maquinário informacional-digital, o que lhe gera-potencialmente-maiores índices de produtividade e de lucratividade na concorrência inter-empresas.

Essas metamorfoses no processo de produção tiveram - e ainda têm - consequências significativas no universo do trabalho: desregulamentação dos direitos sociais; precarização e terceirização da força humana que trabalha, aumento da fragmentação e heterogeneização no interior da classe trabalhadora; enfraquecimento do sindicalismo de classe e incentivo à sua conversão em um sindicalismo mais negocial e de parceria, mais de cúpula e menos de base, mais parceiro e colaborador e menos confrontacionista.

A racionalização do processo produtivo, o forte disciplinamento da força de trabalho, a implantação de novos mecanismos de capital e de trabaIho intensivo, e o envolvimento mais ativo do intelecto no trabalho tornaram-se práticas recorrentes no processo de liofilização organizacional, um processo no qual as substâncias vivas são eliminadas, onde o trabalho vivo é substituído pelo trabalho morto, pelo maquinaria tecno-informacional-digital que hoje tipifica o processo de "enxugamento" das empresas (Antunes, 2010a).

O trabalho em equipe, a transferência das responsabilidades de elaboração, anteriormente realizadas pela gerência científica e agora interiorizadas na própria ação dos trabalhadores - um dos traços do management by streess - são outras marcas for- 
tes presentes nessa processualidade.

Preserva-se um número mais reduzido de trabalhadores dentro das empresas matrizes, mais qualificados, multifuncionais e envolvidos com o seu ideário dos "colaboradores", amplia-se o universo dos terceirizados e temporários no interior (e fora) das empresas, ampliando-se o fosso entre a classe trabalhadora. De um lado, em escala minoritária, o trabalhador "polivalente e multifuncional" da era informacional-digital, capaz de exercitar com mais intensidade sua dimensão mais intelectual. De outro lado, uma massa de trabalhadores precarizados, terceirizados, flexibilizados, informalizados, cada vez mais próximos do desemprego estrutural. A expansão do trabalho part time, as formas como o capital se utiliza da divisão sexual do trabalho, a ampliação do trabalho dos imigrantes, frequentemente ilegais, são outras marcas dessa processualidade potencialmente estranhada e reificada.

Em síntese: a fábrica tayloriano-fordista foi bastante alterada em seu desenho espacial, temporal, em sua organização sócio-técnica, em seus mecanismos de controle do trabalho. Basta mencionar suas manifestações mais fenomênicas: as divisórias desapareceram, o trabalho é organizado em células, combinando multifuncionalidade, polivalência, competição, metas, competências, assumindo uma aparência mais "participativa”, mais envolvente e menos despótica, quando comparada à da fábrica taylorista.

Em contrapartida, entretanto, o trabalho tornou-se mais desregulamentado, mais informalizado, mais intensificado, gerando uma dessociabilidade destrutiva no espaço de trabalho que procura dilapidar todos os laços de solidariedade e de ação coletiva, individualizando as relações de trabalho em todos os espaços onde essa pragmática for possível.

Desse modo, para responder à crise de geração de valor, os capitais, através das práticas toyotistas e da empresa da flexibilidade liofilizada, foram muito além do taylorismo, em busca do que Taiichi Ohno (engenheiro fundador da Toyota) considerava vital, ou seja, da expropriação do intelecto do trabalho. Isso significa dizer que, ao con- trário do taylorismo-fordismo, que exarava um certo desprezo ao saber operário, a pragmática toyotista utiliza-se do saber operário, do intelecto do trabalho, para agregar e ou potencializar mais valor à produção, seja ela prevalentemente material ou imaterial. Os chamados círculos de controle de qualidade ou o incentivo que as empresas fazem para ouvir as sugestões dos trabalhadores e das trabalhadoras são exemplares.

Contemplando traços de continuidade em relação ao fordismo vigente ao longo do século XX, mas seguindo um receituário com claros elementos de diferenciação, a empresa da flexibilidade liofilizada acabou por engendrar novos e mais complexificados mecanismos de interiorização, de personificação do trabalho, sob o "envolvimento incitado" do capital, incentivando o exercício de uma subjetividade marcada pela inautenticidade, isto é, aquela que ocorre quando o incentivo para o exercício da subjetividade do trabalho é sempre conformada pelos interesses das empresas, não comportando nenhum traço que confronte com o ideário do lucro e do aumento da produtividade. O exercício da subjetividade empresarial não comporta, por exemplo, a propositura de uma greve para melhorar as condições de trabalho. Ao contrário, trata-se de um exercício de um subjetivismo anticoletivo, antissindical e intensamente empresarial. Ao contrário, o exercício da subjetividade autêntica dá-se quando não há constrangimentos que "obrigam" o "envolvimento incitado", a realização de práticas empresariais que objetivam melhorar a "integração" entre trabalhadores e empresas. Por isso, o exercício da subjetividade autêntica expressa formas de autonomia, enquanto as formas de subjetividade inautêntica são próprias da heteronomia.

O estranhamento torna-se, então, aparentemente menos despótico, mas intensamente mais interiorizado. Como procurei sintetizar em Os Sentidos do Trabalho:

Ainda que fenomenicamente minimizado pela redução da separação entre a elaboração e a execução, pela redução dos níveis hierárquicos no interior das empresas, a subjetividade que emer- 
ge na fábrica ou nas esferas produtivas contemporâneas é expressão de uma existência inautêntica e estranhada. Contando com maior "participação" nos projetos que nascem das discussões dos círculos de controle de qualidade, com maior "envolvimento" dos trabalhares, a subjetividade que então se manifesta encontrase estranhada em relação ao que se produz e para quem se produz" (Antunes, 2010a, p.130)

\section{E acrescentei:}

Os benefícios aparentemente obtidos pelos trabalhadores no processo de trabalho são largamente compensados pelo capital, uma vez que $a$ necessidade de pensar, agir e propor dos trabalhadores deve levar sempre em conta prioritariamente os objetivos intrínsecos da empresa, que aparecem muitas vezes mascarados pela necessidade de atender aos desejos do mercado consumidor. [...] Mais complexificada, a aparência de maior liberdade no espaço produtivo tem como contrapartida o fato de que as personificações do trabalho devem se converter ainda mais em personificações do capital. Se assim não o fizerem, se não demostrarem estas "aptidões", ("vontade", "disposição" e "desejo"), são substituídos por outros trabalhadores ou trabalhadoras que demonstrem "perfil" e "atributos" para aceitar estes "novos desafios" (p.130).

E, nesse processo de envolvimento interativo, ampliam-se e complexificam-se as formas da reificação, distanciando a subjetividade que trabalha do exercício de uma atividade autêntica e autodeterminada. A aparência de um despotismo mais ameno, plasmado pela sociedade produtora de mercadorias desde o seu nível mais microcósmico, tende a aprofundar e interiorizar ainda mais a condição do estranhamento.

Desse modo, a alienação ou, mais precisamente, o estranhamento (Entfremdung) do trabalho encontra-se, em sua essência, preservado, ainda que dotado de novas engrenagens e mecanismos de funcionamento. Fenomenicamenteminimizado pela redução da separação entre a elaboração e a execução, pela redução dos níveis hierárquicos no interior das empresas, a subjetividade que emerge na fábrica ou nas esferas produtivas mais avançadas e de ponta parece assumir o exercício de uma subjetividade inautêntica e estranhada, para recorrer à formulação de N. Tertulian (1993).

Além do saber operário, que o fordismo expropriou e transferiu para a esfera da gerência científica, para os níveis de elaboração, conforme nos referimos anteriormente, a nova fase do capital, da qual o toyotismo é a melhor expressão, retransfere o savoir faire para o trabalho, mas o faz apropriando-se crescentemente da sua dimensão intelectual, das suas capacidades cognitivas, procurando envolver mais forte e intensamente a subjetividade operária.

Mas o processo não se restringe a essa dimensão, uma vez que parte do saber intelectual é transferido para as máquinas informatizadas, que se tornam mais inteligentes, reproduzindo parte das atividades a elas transferidas pelo saber intelectual do trabalho.

Como a máquina não pode suprimir o trabalho humano, ela necessita de uma maior interação entre a subjetividade que trabalha e a nova máquina inteligente. E, nesse processo, o envolvimento interativo maquínico pode aumentar ainda mais o estranhamento do trabalho, ampliando as formas modernas da reificação, distanciando ainda mais a subjetividade do exercício de uma cotidianidade autêntica e autodeterminada.

E mais: se o estranhamento permanece e mesmo se complexifica nas atividades de ponta do ciclo produtivo, naquela parcela aparentemente mais "estável" e inserida da força de trabalho que exerce o trabalho intelectual abstrato, o cenário é ainda mais intenso nos estratos precarizados da força humana de trabalho, que vivenciam as condições mais desprovidas de direitos e em condições de instabilidade cotidiana, dada pelo trabalho part-time temporário, precarizado, para não falar nos crescentes contingentes que vivenciam o desemprego estrutural. Sob a incerteza e a superfluidade dadas pela condição da precarização ou de risco do desemprego, o estranhamento pode assumir formas ainda mais intensificadas e mesmo brutalizadas, pautadas pela perda (quase) completa da dimensão de humanidade (Antunes, 2010).

Nos segmentos mais intelectualizados da classe trabalhadora, que realizam atividades próprias do que hoje se denomina como trabalhos vinculados às tecnologias de informação e comu- 
nicação, à pesquisa e ao design, as formas de reificação têm uma concretude particularizada, mais complexificada (mais "humanizada" em sua essência desumanizadora), dada pelas novas formas de "envolvimento" e interação entre trabalho vivo e maquinaria informatizada (2010).

Já nos estratos mais penalizados pela precarização e pelo desemprego, a reificação é diretamente mais desumanizada e brutalizada em suas formas de vigência. O que apresenta um quadro contemporâneo pautado pelos estranhamentos, reificações e alienações que parecem mais se ampliar do que se reduzir; diferenciados quanto à sua incidência, mas vigentes como manifestação que atinge a totalidade do trabalho social (2010).

Foi perseguindo essas diferenciações existentes no complexo social do estranhamento que a obra de maturidade de Lukács ofereceu uma diferenciação rica, pouco explorada, entre as reificações inocentes e as reificações estranhadas (ou alienantes).

Em suas palavras: é na ontologia da vida cotidiana que florescem as reificações que propiciam os estranhamentos:

... de um lado, os comportamentos sociais em si 'inocentes' do ponto de vista do estranhamento, quando atingem em profundidade a vida cotidiana, reforçam a eficácia daqueles outros comportamentos que já operam nessa direção; de outro lado, os indivíduos são tanto mais facilmente envolvidos, pelos impulsos ao estranhamento [...], quanto mais as suas relações vitais são por eles percebidas em termos abstratos, reificados e não de modo espontaneamente processual (Lukács, 1981, p.643).

\section{E acrescenta Lukács:}

De fato, quanto mais a vida cotidiana dos homens [...] cria formas e situações de vida reificantes, com maior facilidade o homem cotidiano se adapta a elas entendendo-as, sem nenhuma resistência intelectual e moral, como 'dados de natureza', pelos quais em média - por não serem inelutáveis em princípio - pode haver uma menor resistência frente às autênticas reificações estranhadas. Aqui se habitua a determinada dependência reificada e isso propicia - repitamos: como possibilidade e não de modo socialmente necessário - uma adaptação geral também nos confrontos de dependências estranhadas (p.643) .
Lukács retoma, então, a formulação marxiana presente em o fetichismo da mercadoria, para avançar na caracterização dos suportes materiais da reificação em sua "espectral objetividade". E, ao discorrer sobre o caráter misterioso de mercadoria e seu símile na esfera da religião, acrescenta que é nesse momento que afloram as diferenciações existentes entre as reificações inocentes e aquelas que estão sedimentados a partir da "espectral objetividade" do mundo da mercadoria (1981, p.644).

Nicolas Tertulian explorou sugestivamente as pistas de Lukács, presentes no último volume de sua Ontologia, que acabamos de indicar. E oferece também uma sugestiva interpretação: segundo ele, as reificações inocentes ocorrem quando há a condensação das atividades em um objeto, em uma coisa, propiciando a "coisificação" das energias humanas, que funcionam como reflexos condicionados e que acabam por levar às reificações inocentes. Nesse caso, a subjetividade é reabsorvida no funcionamento do objeto, sem efetivar-se uma “alienação" propriamente dita (Tertulian, 1993, p.441). As reificações estranhas, que configuram o que Tertulian traduz como reificações alienantes, manifestam-se nas atividades onde a subjetividade

... é transformada em um objeto, em um "sujeitoobjeto”, que funciona para a auto-afirmação e a reprodução de uma força estranhada. O indivíduo que chega a auto-alienar suas possibilidades mais próprias, vendendo, por exemplo, sua força de trabalho sob condições que lhe são impostas, ou aquele que, em outro plano, sacrifica-se ao 'consumo de prestígio', imposto pela lei de mercado (p.441).

Ou seja, enquanto as reificações inocentes ainda não se encontram moldadas pela forma-mercadoria em sua plena vigência, as reificações alienantes são típicas expressões do fetichismo da mercadoria. Claro, portanto, que aqui a recorrência a Lukács e à sua distinção acima indicada não têm a pretensão (o que seria um grave equívoco) de transplantá-la para o capitalismo de nossos dias, mas tão somente indicar que há um fértil terreno analítico que pode e deve ser explorado para que haja uma melhor compreensão dos fenômenos atuais da alienação e dos estranhamentos. 


\section{À GUISA DE CONCLUSÃO}

Se, na empresa tayloriano-fordista, o despotismo é mais explícito em sua conformação, e o estranhamento ou o modo de ser da coisificação acaba sendo mais "direto", na fábrica da flexibilidade liofilizada, diferentemente, as novas técnicas de "gestão de pessoas", as "colaborações" e as parcerias" procuram "envolver" as personificações do trabalho de modo mais interiorizado, procurando convertê-los "voluntariamente" em uma espécie de autocontroladores de sua produção, em déspotas de si mesmos.

A compreensão, portanto, desses novos mecanismos e dessas novas engenharias da sujeição nos leva a perceber formas e modalidades mais interiorizadas e complexificadas de alienação e de estranhamento, das quais as flexibilizações, os ganhos por produtividade e lucratividade (a participação nos lucros e resultados) e os envolvimentos são elementos cada vez mais presentes. E, nas diferenciações e complexificações existentes dentro dos processos de alienação e estranhamento presentes no capitalismo contemporâneo, um bom começo pode ser partir das indicações finas e inspiradas que encontramos na analítica de Lukács para mergulhar mais profundamente no mundo do capital de nossos dias, de seus estranhamentos e de suas alienações.

(Recebido para publicação em 23 de janeiro de 2011) (Aceito em 19 de abril de 2011)

\section{REFERÊNCIAS}

ANTUNES, Ricardo. Adeus ao trabalho?15.ed. São Paulo: Cortez, 2010.

. Os sentidos do trabalho. 12.ed. São Paulo: Boitempo, 2010a.

O mundo do trabalho em mutação: da pragmática da especialização fragmentada à pragmática da liofilização flexibilizada. In: SILVA, Maria Vieira; CORBALON, Maria Alejandra (Org.) Dimensões políticas da educação contemporânea. São Paulo: Alínea, 2009.

GRAMSCI, Antônio. Escritos políticos. Rio de Janeiro: Civilização Brasileira, 2004. v.1.

HUWS, Ursula The making of a cybertariat (virtual work in a real world). Nova Iorque/Londres: Monthly Review Press/The Merlin Press, 2003.

LUKÁCS, Gyorg Ontologia dell'essere sociale, II Roma: Ed. Riuniti, 1981. v.1. $\overline{1981 \mathrm{v}} 2$. Ontologia dell'essere sociale. II Roma: Ed. Riuniti,

MARX, Karl. O capital I. Rio de Janeiro: Ed. Civilização Brasileira, 1971. v.1.

Extractos de lectura - James Mill. In:

Obras de Marx y Engels, OME 5: manuscritos de Paris y anuários franco-alemanes 1844, Barcelona: Grijalbo, 1978

Manuscritos econômico-filosóficos. São Paulo: Boitempo, 2004

MÉSZÁROS, István. A teoria da alienação em Marx. São Paulo: Boitempo, 2006.

RANIERI, Jesus. A câmara escura: alienação e estranhamento em Marx. São Paulo: Boitempo, 2001.

TERTULIAN, Nicolas. Le concept d'aliénation chez Heidegger et Lukács. Archives de Philosophie- Reserches et Documentation. Paris, n.56, jul./set., 1993. 


\section{THE EXERCISE OF SUBJECTIVITY: the innocent reifications and the estranged reifications}

\section{Ricardo Antunes}

This text explores, analytically and empirically, the problem of alienation and (or) estrangement, seeking to help in the intellection of the socio-historical foundations that provide it to flourish within the modern capitalist enterprise. To do so it performs the following movements: first, starting with Marx's seminal theoretical concepts, it attempts to indicate the different forms assumed by the alienaton and (or) estrangement throughout the twentieth century and early twentyfirst century, exploring some of its main features. In its second motion, it outlines a phenomenology of subjectivity, exploring, as a hypothesis, the rich analytical possibilities existing in Lukács's mature work, in particular his notions of innocent reification and stranged reification, fertile as clues to understand this social phenomenon in capitalism today.

KEYwords: alienation and estrangement, capitalism and reification, Taylorism, Toyotism and subjectivity.

\section{LES EXERCICES DE LA SUBJECTIVITÉ: les réifications innocentes et les réifications grotesques}

\section{Ricardo Antunes}

Ce travail examine de manière analytique et empirique le problème de l'aliénation et (ou) de l'étrangeté afin de contribuer à l'intellection des bases socio-historiques qui permettent son éclosion au sein de l'entreprise capitaliste moderne. Pour ce faire, on procède selon les mouvements suivants : partant des concepts théoriques séminaux de Marx, on essaie tout d'abord de montrer les différentes formes assumées par l'aliénation et (ou) l'étrangeté, au cours du XXe siècle et au début du XXIe siècle, en approfondissant quelques-unes de ses caractéristiques principales. Ensuite, on ébauche une phénoménologie de la subjectivité, en prenant comme hypothèse les riches possibilités d'analyses qui existent dans le travail mature de Lukács, en particulier dans ses notions de réifications innocentes et de réifications grotesques, considérées comme des pistes fertiles pour la compréhension de ce phénomène social dans le capitalisme d'aujourd'hui.

Mots-CLÉs: aliénation et étrangeté, capitalisme et réification, taylorisme, toyotisme et subjectivité.

Ricardo Antunes - Doutor em Sociologia pela USP. Professor Titular de Sociologia no Instituto de Filosofia e Ciências Humanas da UNICAMP. Pesquisador do CNPq. Coordena as Coleções Mundo do Trabalho (Boitempo Editorial) e Trabalho e Emancipação, pela Editora Expressão Popular. Autor, entre outros, dos livros: Adeus ao Trabalho? 14a ed., (Ed. Cortez), publicado também em outros países; Os sentidos do trabalho (Ed. Boitempo), $9^{a}$ edição, publicado em outros países; A desertificação neoliberal ( Ed. Autores Associados. 2.ed.) e de artigos em revistas diversas, dentre as quais: Herramienta, Buenos Aires; Revista Latinoamericana de Estudios Del Trabajo; Margem Esquerda; Cadernos IHU Ideas, Unisinos; Contre Temps; Shiftwork International Newsletter; Política e Sociedade; Revista Crítica de Ciências Sociais; Caderno CRH. 